\title{
The Dynamic Factors of Desertification and Their Impact on Ecosystems
}

\section{Ciprian Tudor ${ }^{1}$, Cristinel Constandache ${ }^{1}{ }^{*}$, Mihai Hapa ${ }^{2}$, Lucian Dincă ${ }^{3}$}

1 "Marin Drăcea" National Institute for Research and Development in Forestry, Republicii Street, no.7, Focșani, 620018, Romania, 0237.621541, 230481,

2 "Marin Drăcea" National Institute for Research and Development in Forestry, Isaccei, no.25, Tulcea, 820166, Romania, 0240.512159, 0240.506117,

3 "Marin Drăcea” National Institute for Research and Development in Forestry, Cloșca

Street, no. 13, Brașov, 500040, Romania, 0268.419936, 0268. 415338

E-mail: cipriantudor95@yahoo.com; cicon66@yahoo.com; ionutmihaihapa@gmail.com; dinka.lucian@gmail.com

\author{
*Corresponding author details: Cristinel Constandache; cicon66@yahoo.com
}

\begin{abstract}
Even from the middle of the 19th century desertification was considered a controlled artificial process with anthropic factors as the main cause. Forest treatments applied in tropical forests in an incorrect manner have led to soil degradations and a destabilization of climatic and hydrologic regimes. In these conditions, desertification and its indicators have regressed in regard with agricultural and forestry productivity. This was caused by a non-sustainable management characterised by exploitation anthropic activities realized in an uncontrolled procedure. In 1994, the desertification definition was updated by introducing climatic factors and abusive grazing as consequences of field degradation. The main purpose of this article is to understand the concept of" desertification" and to elaborate a qualitative analysis based on published scientific articles in order to investigate the influence factors that led to the apparition of this phenomenon in Europe, Asia, Latin America and Africa. The scientific objectives consist in analysing the evolution of desertification in different affected regions as well as to analyse the influence factors that led to the ecological destabilization of agricultural and forestry domains through degradation and a reduction of silvo-biologic productivity. The results were based on analysing 74 articles published in specialty agricultural and forestry journals or magazines by institutions or associations of owners, managers of waters and forests, forestry specialists, academicians and ecologists. They have all studied the present problem posed by desertification as well as modern applied methods for rehabilitating ecologic conditions in degraded ecosystems from semi-arid, arid and extremely arid areas.
\end{abstract}

Keywords: aridity index; biophysical models; desertification; degradation; climate change

\section{INTRODUCTION}

Desertification is a global phenomenon that mainly affects segments from agriculture and silviculture. This also extends to humanity as it brings negative effects on human health and wellbeing. As a complex phenomenon, desertification was studied and monitored from the end of the XIXth century as local communities, owners or associations signalled it in order to re-establish the ecological optimum and to restore silvo-ecological conditions from arid, semi-arid and extremely arid areas. The concept of "desertification" was used for the first time in 1927 in Tunisia by Lavauden who mentioned the "purely" artificial process caused by human acts" [30] in the context of low productivity as a cause of improper field management. However, Aubreville was the one that laid the foundation for the "desertification" concept by using it constantly [3]. He mentioned that cuttings from West Africa have led to field erosion and degradation, known as "desertification". UNCCD adopted a new definition in 1994 [39] where the main difference is represented by inserting the climatic factor as a destabilizing factor together with improper management and grazing. "Desertification" poses major social challenges as a result of reducing the ecosystem's silvoproductive capacity to offer non-wood and wood products, services and prime materials for food and water. The phenomenon affects approximately 200 million people and leads to a decrease in human wellbeing [1].

If we consider the globalisation of this phenomenon, the notion was associated with the reduced capacity of ecosystems to fulfil proper services for long periods of time and failing in balancing the request and offer in dry and arid surfaces. The main idea is represented by an accentuated decrease of biological and/or economic productivity attributed to the environment's ability to fulfil ecosystem services. These losses are associated with a percentage increase of uncovered soils whose main consequence is vegetation loss. Furthermore, reliability intervals were assigned for desertification intensity as follows: 
- average reliability- for biodiversity loss in regions located in dry areas;

- high reliability-reducing productivity and agricultural incomes;

- losses in ecosystem services through the spread of invasive species;

- depletion of subterranean waters through supra extraction;

- the precarious management of fields, especially during drought periods [32, 33].

The most important drivers for desertification feedback are:

- destabilizing anthropic factors (i.e. soil erosion through agricultural activities that process it);

- soil salinity;

- field degradation near a water source (the conversion of forests and agricultural fields in agricultural cultures as a result of an increased request of food for people) $[10,12]$.

- recent climatic changes- vegetation fires, the extension of invasive species, aerosol, global warming, anomalies in sea surface temperatures (SST) [19, 33], [11, 42].

- Many institutions have socio-economic policies and factors that contribute indirectly to desertification, such as:

- the insecurity of land properties;

- the lack of property ownership titles;

- the lack of access towards markets and rural consultancy services;

- the lack of knowledge and technical abilities;

- distortion of agricultural prices, support and subventions.

\section{MATERIALS AND METHODS}

\section{Data collection}

In the present paper, materials were collected from numerous documentary resources such as scientific publications, annual or periodical reports and books. This was complemented by studying strategies for rebutting desertification from management plans adopted by each region. The Rio Earth Summit from 1992 resulted in identifying the true challenges in long lasting development mainly caused by two decisive factors that lead to "desertification": climatic changes and reducing biodiversity.

In 1994, the United Nations Convention to Combat Desertification (UNCCD) was the single international accord that bridges the environment and the sustainable development of fields [40]. In 2007, the main objective of the strategy elaborated at 10 years from UNCCD was to create a global partnership for preventing field degradation and desertification by reducing the effects of drought from arid areas. In addition, the strategy intended to remove poverty from rural communities and to create resilience conditions in the jeopardized environments. A total number of 195 parts have participated at the convention and have approached the issue of living conditions from affected areas, improving field and soil productivity and to reduce the extension of drought effect. As field dynamic is interconnected with climate and biodiversity, UNCCD Convention has closely collaborated with other two conventions from Rio, namely: Biological Diversity Convention (CBD)

The Framework Convention of the United Nations regarding climatic changes (UNFCCC).

\section{Methodology approach}

The documentation activity regarding the desertification phenomenon is toilsome due to the concepts that have led to the exemplification of all processes and procedures involved in the fundamentation of desertification signs/indexes. This is complemented by national and international policies, national evaluation and restoration priorities, or strategic foundations needed to reach the intended objectives. The work method that led to the elaboration of this article consisted in creating a database with informatic resources from scientific research platforms/engines (google academic, web of science, google scholar and so on). The database also focused on exposing all the feedback regarding soil, climate and vegetation as well as the interaction between them and the proper method for implementing restoration works. Furthermore, we have analysed the negative impact of desertification drivers from countries or regions that have a high risk of drought from South Africa, Latin America, Asia and Europe. The method of keyword research has helped in identifying the scientific articles that were based on through studies realized by specialists. These articles were focused on desertification at a global level and contain special techniques for environment restoration, information about the resilience capacity of forest ecosystems and future projections for desertification consequences. With this purpose in mind, we have accessed simple keywords (e.g drought, desertification, climate change, vegetation and so on) and combinations of two or more words (e.g climate change and drought, drought and desertification, climate change and desertification, desertification strategies). Google scholar has produced a number of 2.890.000 articles for the "drought" keyword while we have selected the most relevant articles. The same search engine has revealed that "desertification" was used in 387.000 scientific articles. This fact reveals the late appearance of this concept. The methods used for the creation of this article are essential for scientific activities concerning the documentation and review of "desertification" contents that were analysed over two decades and implemented especially in areas with a high risk of aridity.

\section{RESULTS AND DISCUSSIONS}

\section{Measures for identifying semiarid and arid areas}

From the perspective of locating arid regions and classifying dry areas, most situations use precipitation quantification (annual averages) and calculating the aridity index (EVP/P). In this way, aridity is a climatic change manifested on a long term and caused by the low quantum of annual average precipitations $[24,38]$. Investigations based on the variability of the aridity index (AI) show that the surface occupied by dry areas is of approximately $46.2 \%( \pm 0.8 \%)$ from the global surface of fields $[28,36]$. Areas with extreme aridity $(\mathrm{AI}<0.05)$ are included in dry areas but are excluded from the "desertification" definition [40]. However, even if this indicator has a considerable representability, the soil water content undermines it and becomes significant from an ecohydrological point of view. Humidity conditions from the soil become dependent on the precipitations correlated with evapotranspiration loses and the soil's characteristics properties $[8,13]$. It is well known that the aridity index restores the zoning of dry climates even though they are more characterised by an increased seasonal variability (especially for dry or humid seasons). These factors surely determine the ecosystem's restriction of water supply [19].

In the same way in which different forest definitions determine the afforested surface of a state/region, the distribution of areas under desertification conditions becomes a very delicate subject.

This is caused by the fact that desertification definitions differ from one entity to another even though it represents a consensus and a global urgency. Monitoring semi-arid, arid and extremely arid areas was realized by the efforts of 
organizations such as WOCAT (Global presentation of conservation approaches and technologies), LADA (Evaluating field degradation in dry areas) and DESIRE (Desertification Mitigation and Remediation of Land). The three organisations have jointly developed a mapping instrument for the current coverage of areas, as well as for the field degradation types and tendencies [37]. As such, a variety of feedback mechanisms have resulted that involve processes such as: a) changing soil properties and field degradation $[2,5,29]$; b) combining vegetation and climate; c) changes in the composition of plant species.

Many countries adopted the following methods in approaching the desertification issues:

- the method of residual tendencies (RESTREND) for explaining rain variability [23];

- methods for identifying critical points and finding major changes in vegetation trends [41];

- methods for explaining explicitly the effect of fertilization with $\mathrm{CO}$;

- methods based on acoustic measurements (microwaves) and on the Vegetation Optical Depth (VOD) technology that are strongly connected with estimating the water content in the total subterranean biomass [31].

Considering the later desertification definitions, climatic variations and anthropic activities can have a positive effect. However, under modern auspices, the effect can also be negative by limiting the ecosystems' potential of returning to their equilibrium state. As such, two states can exist in the context of desertification theories. These states, rendered in Figure number one are a vegetative state (undegraded) and a non-vegetative state (degraded) [19]. A stable ecosystem (a) represents the ecosystem's capacity for returning to its initial state. Resilience (b) represents an attribute of the equilibrium state that is expressed through the ability of a functional system to return to its ulterior state after the apparition of a destabilizing factor. Desertification represents the transition between the two stable/unstable states. The last section (c) represents the typical scheme of a desertification feedback.
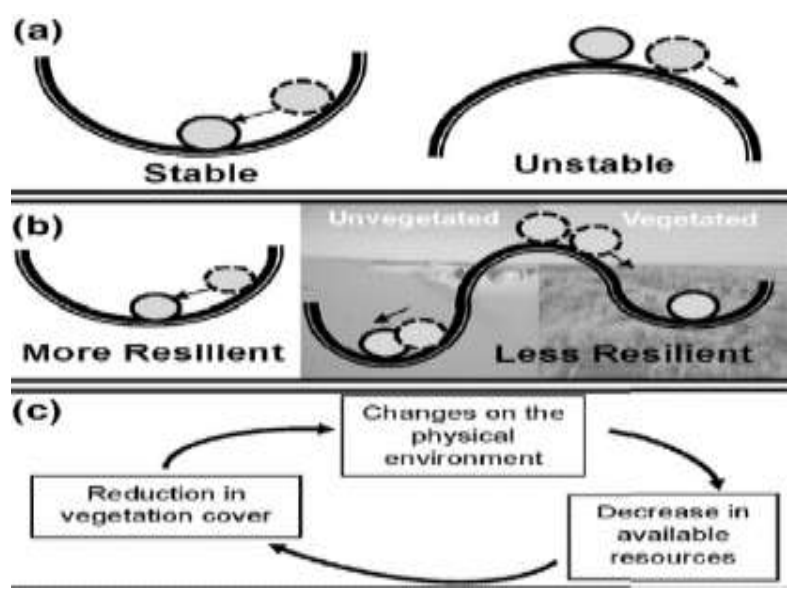

FIGURE 1: Ecosystem equilibrium [19]

Another monitoring method is represented by satellite tele detection (Remote Sensing). This is used for investigating long term vegetation changes and for identifying the dry areas that suffered from desertification [15]. The most used tele detection coefficient is the vegetation coefficient, expressed through the NDVI method which evaluates the standing quantity of biomass $[4,16,17]$.

\subsection{Biophysical methods}

Biophysical methods use global databases that describe climate and soil characteristics in order to create potential productivity classes by monitoring field degradation [26].
However, these models have limits that lead to uncertainty regarding the structure, spatial scale and demands of databases as well as for the spatial heterogeneity of social and economic conditions. Many of these models have been used in expressing the vegetation's productivity potential and its evolution through changes caused by drivers (shaping factors) [8]. Numerous studies have explored factorial simulation models used for investigating the causes of vegetation changes [44] and the soil's erosion rate on extensive areas from South America, Africa and Asia [6]. Consequently, current trends are represented by using new methods and exploring modelling in monitoring factors that lead towards the notion of field surface desertification. This is sustained by the rapid need for observations through digital tele detection instruments.

\subsection{Field degradation}

Three main modelling processes can be attributed for field degradation and the decrease of soil fertility, namely: removing soil particles rich in nutrients under the action of water and wind erosion on fields with agricultural usage; decreasing the soil water content due to soil compaction and reducing soil permeability and its capacity to retain water (intensely grazed fields); accumulating salts and other toxic substances that obstruct vegetation growth and reinstallation (low areas). Most of the time, these processes are combined and lead to complex degradation forms [10].

\subsubsection{Soil erosion}

A documented case for soil degradation is associated with the development of agriculture and the intensive growth of animals in North America. In this region, the field's extensive usage, combined with a prolonged drought has caused in 1930 a major erosion precedent. This led to a massif decrease in the soil's properties and to drastic sand/dust storms. In order to reduce this cataclysm known as „the Dust Bowl”, the USA government has implemented a program (CPR) that ensured stimulants for farmers that transformed eroded surfaces in pastures. In Romania, numerous studies have proved the efficiency of the vegetal rug and forest vegetation (shrubs mixed with grasses from the spontaneous flora) in controlling soil erosion. These species occupy the lower level and are carefully selected when introduced into planting schemes, after extensive research about the stational conditions present in that area $[10,12]$

\subsubsection{Reducing soil humidity}

Changes in soil texture and structure as well as its loss in retaining water can have negative effects by losing fine soil particles. At the same time, the relation between soil humidity and vegetation can lead to different feedbacks. In this case, tree associations (with an increased consistency) increase the soil's capacity for water infiltration but reduce water evaporation from the soil's surface. As such, the water content is high under the crown but not between the crowns. In both cases, the loss of tree associations can be correlated with water losses from soil and with the plant's incapacity for reinstallation (colonization). Numerous studies have concluded that the significance of this feedback is accentuated by a decrease in annual average precipitations.

\subsubsection{Soil salinity}

The decrease of soil productivity can be rendered by an increase in soluble salts from the soil's content. Cutting local vegetation (natural fundamental forest types) and replacing them with grove/monoculture/agriculture species has led to an increase in evapotranspiration and salt accumulation. Saline and sodic soils appear naturally in arid, semi-arid and sub-humid dry areas because of the subterranean mineralized water. 
Secondary salinization appears when the concentration of salts dissolved in water and soil is increased by anthropic processes (applying irrigation schemes that are poorly managed). The increase of the sea's level as a result of ice melting and the intrusion of the sea's water represents a threat for soil salinity and underground waters in the context of climatic and hydrologic changes. This phenomenon implies the accumulation of soluble salts at the soil's surface, having a negative effect on economic and ecologic productivity. Salts destroy soil structure and reduce its porosity and permeability. It can be said that salts do not act only on soils but affect water properties in the same degree (ex. irrigating agricultural cultures with improper water can destroy cultures and contaminate clean water). In correlation with vegetation, species that have a higher tolerance towards salinity (halophile) must be promoted due to their capacity to survive at a higher level of salinity near their roots. A specific case was present in Murray-Darling Basin from Australia where the conversion of a forest into an agricultural field has decreased the water's level in depth at the expense of mobilising salts in the unsaturated soil. The salts were transported in the radicular system. In this situation, the only solution was to offer a supply with clean water, which can be very expensive, especially in dry areas.

\section{The feedback between vegetation and climate}

A first aspect is represented by the decrease of precipitation recycling, namely reducing evapotranspiration and increasing water loss through leakage due to vegetation loss. In the case in which recyclable precipitations represent a good part of total precipitations, field degradation can be affected positively [43].

Another aspect or feedback is represented by the vegetation's capacity to change the surface energy flux (albedo, soil humidity and root depth - figure 2). Its negative values can cause surface cooling and reducing convective precipitations.

Investigations for the desertification from Sahel-Sahara Central Mongolia, have shown that the vegetation-climate feedback was negative for the stable balance favourable for degradation. In simpler terms, an increase in the surfaces covered with vegetation has favoured abundant precipitations and the retention of a high-water volume.

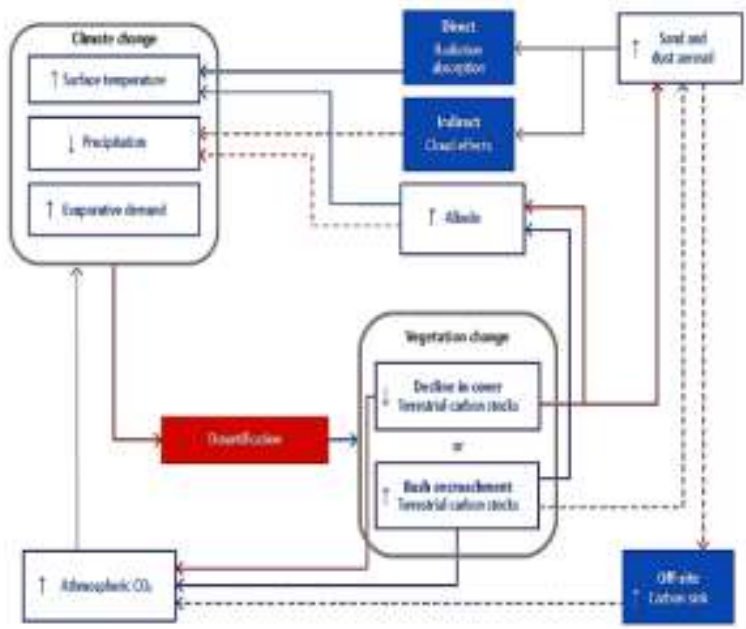

FIGURE 2: The main schematic ways through which desertification can be nurtured by the climate's effect [33]

Another aspect concerning the vegetation-climate relationship is given by the intensification of dust emissions because of reducing surfaces covered by vegetation.
On their turn, they have reduced the apparition of precipitations, affecting indirectly the installation or reinstallation of vegetation on those surfaces.

Certain researchers have concluded that dust aerosols can affect clouds at a microphysical level under the form of cloud condensation nucleus (CCNs). They prevent their formation at a level that allows precipitations and can also change the cloud's radiative properties [27]. The heating of the dust layer can relatively change humidity and atmospheric stability that can change the clouds' life expectancy and water content. This is also known as semi-direct effect. The changes of subterranean waters can affect vegetation and cause atmospheric dust [20]. The heating of fine and coarse dust particles from the soil's surface stimulates snow melting. This leads to a decrease of soil humidity through infiltration and an increase of the evapotranspiration's capacity.

The variability of the indirect effects is higher than the direct effects, based on the types and quantities of aerosols present in the atmosphere. The general tendency is their increase in number. Reducing the dimension of raindrops determines an increase in cloud reflectivity, a fact that implies a diminishing of precipitation chances. These effects are known as radiations with aerosols and aerosolcloud interactions [7].

An increased trust is manifested towards the negative relationship between the greening caused by vegetation and the appearance of dust storms [21].

\subsection{The change in composition of plant species}

This process represents the interaction between the biotic and abiotic factor after a destabilizing event. The apparition of fertile shrub islands in combination with pastures or in special cases with degraded fields (figure 3), represents a particular case of this process. The process appears especially on surfaces with uncovered soil, strong winds and a high erosion degree caused by water or wind. Several factors such as the atmosphere's $\mathrm{CO} 2$ concentration, $\mathrm{N}$ deposits, excessive grazing [35] and even fires [34] can induce this transition from pasture to shrub associations. It is important to note the fire-vegetation feedback where the fire management can increase the surface covered by shrubs at the expanse of herbaceous cover in order to reduce fire intensity and frequency. The strictly climatic feedback implies associating shrubs with a microclimate that will reduce later the mortality caused by frost or drought. Another perspective for changing the composition can be observed in dry (arid) ecosystems where local species invade shrub associations (Salix rosmarinifolia in Letea Forest, Tulcea County, Romania).

Usually, this invasive phenomenon is caused by an increase in fire frequency, with destroyed shrubs/trees and the invasive species colonizing rapidly the space. This fact causes a loss in biodiversity, leading to soil erosion and an intensification of desertification. If we consider the anthropic factor as destabilizing factor, a typical example is represented by the construction of irrigation and drilling systems with the purpose of increasing the production of animals and suggesting that a lack of water in certain pastures decreases farming productions. This fact involves the supra-exploitation of pastures located near irrigation/drilling systems without considering the vulnerability of arid fields and increasing desertification. This situation can also lead to adopting an improper field and animal management and represents a limitative factor where the population becomes sedentary, stopping transhumance. 


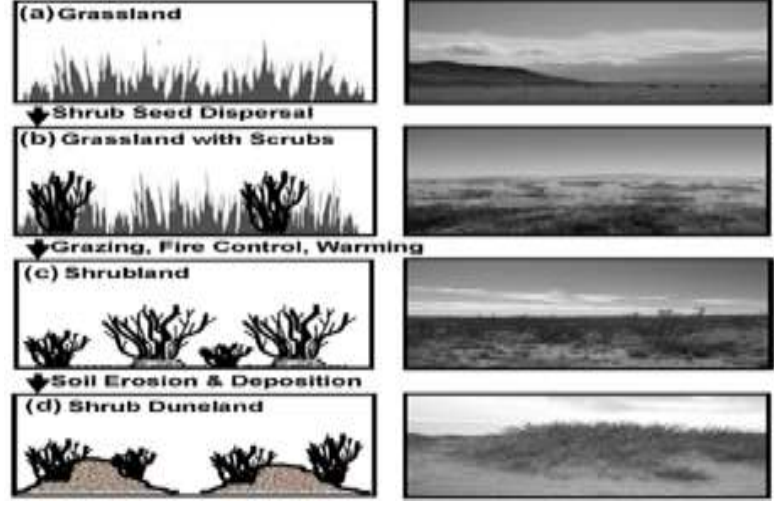

FIGURE 3: The process of installing shrubs/shrub islands [19]

\section{Specific indicators for degraded lands}

The desertification dynamic is very unpredictable from the perspective of ecosystem management. In this way, the conditions that limit the generation of a destabilizing phenomenon must be known and followed (ex. the maximum tolerance limit of an ecosystem in the face of a destabilizing factor up to the production of the disequilibrium/ unstable state). If we consider the fact that desertification represents a long-lasting process, its monitoring and solving can last decades. Furthermore, certain indexes can be measured based on the soil's properties, hydrologic conditions or plant biology. Changes in plant composition, seed sources and viability can be indexes cat will evaluate a surface's transition towards a desertification state as well as the ecosystem's ability to recover. Changes in soil properties can be quantified as an index such as the soil's content of nutrients [14, 22] or its capacity to retain water [9, 18]. Quantifying water evaporation and transpiration can be an extremely important factor as evaporation represents an unproductive way of eliminating water in the atmosphere. In some cases, in can even contribute to soil salinity and to desertification.

\section{CONCLUSIONS}

Desertification is a complex process, usually associated with the process of field degradation. The main cause for its appearance is represented by socio-economic factors and climatic changes. The consequences of desertification effuse over semi-arid, arid or extremely arid areas and consists in losing the soil's fertile layer through erosion processes. These involve a decrease of in water retention capacity and in vegetation instalment. In order to identify dry areas, we have used the values of the aridity index as well as methods based on GIS satellite technologies supplied by WOCAT, LADA and DESIRE organizations. Approaching the desertification issue was realized by thorough studies regarding precipitation variability and quantum, monitoring current vegetation and its evolution on certain areas, storing C02, emissions and applying ultrasound technologies for estimating humidity from the subterranean biomass. Controlling desertification is a challenge for the long-lasting management of fields and involves a lot of attention from the involved political associations. Strategies for rebutting desertification are based on a scientific and technologic support, multisource investments, realizing workshops and training programs that can all stimulate an international cooperation.

\section{REFERENCES}

[1] Adeel, Z., Bogardi, J., Braeuel, C., Chasek, P., NiamirFuller, M., Gabriels, D., King, C., Knabe, F., Kowsar, A., Salem, B., Schaaf, T., Shepherd, G., Thomas, R. (2006). Desertification and the International Policy Imperative Algiers, Algeria, 17-19 December.
[2] Andriucă, V., Macrii, L. (2017), Indicii fizico-mecanici şi utilizarea lor în evaluarea gradului de degradare antropică a solului, Stiinta agricola, l (2), 12-18.

[3] Aubreville, A. (1949). Climats, forêts et désertification de l'Afrique tropicale, Société d'Editions Géographiques, Maritimes et Coloniales, Paris, France, pp 351.

[4] Bai, Z.G., Dent, D.L., Olsson, L., Schaepman, M.E. (2008). Proxy global assessment of land degradation, Soil Use Manag., 24, 223-234.

[5] Bireescu, L., Bireescu, G., Constandache, C., Sellitto, M.V., Dumitru, M., Anton, I. (2001). Ecopedological Research for Ecological Rehabilitation of Degraded Lands from Eastern Romania. Soil \& Water Res., 5, 2010 (3), 96-101.

[6] Borrelli, P., Robinson, D.A., Fleisher, L.R., Lugato, E., Ballabio, C., Alewell, C., Meusburger, K., Modugno, S., Schutt, B., Ferro, V., Bagarello, V., Oost, K.V., Montanarella, L., Panos Panagos, P. (2017). An assessment of the global impact of 21st century land use change on soil erosion, Nat. Commun., 8 (2013).

[7] Boucher, O.D., Randall, P., Bretherton, A.C., Feingold, G., Kerminen, V.M., Kondo, Y., Liao, H., Lohmann, U., Rasch, P., Satheesh, S.K., Sherwood, S., Stevens, B., Zhang, X.Y. (2013). The Physical Science Basis. Contribution of Working Group I to the Fifth Assessment Report of the Intergovernmental Panel on Climate Change [Stocker, T.F., D. Qin, G.-K. Plattner, M. Tignor, S.K. Allen, J. Boschung, A. Nauels, Y. Xia, V. Bex and P.M. Midgley (eds.)], Cambridge University Press, Cambridge, United Kingdon and New York, NY, USA, p. 571-657.

[8] Cai, X., Zhang, X., Wang, D. (2011). Land availability for biofuel production, Environ. Sci. Technol., 45: 334-339.

[9] Cântar, I.C., Dincă, L. (2018), The forest soils from Arad County, Annals of the University of Craiova, Series Biology, Horticulture, Food produce processing technology, Environmental engineering, 23(59): 345351.

[10] Constandache, C., Dincă, L., Tudose, N.C., Panaitescu, C. (2018a). Protecting surface water resources through silvicultural methods, International Symposiuum "The environment and the industry", Simi 2018, proceedings book Section Pollution Assessment \& Management Systems, 276-284.

[11] Constandache, C., Dinca, L., Popovici, L., Braga, C., Blaga, T. (2018B). The effect of climatic changes over some Romanian forest ecosystems, 18th International Multidisciplinary Scientific Geoconference SGEM 2018, Conference proceedings, Volume 18, Water resources, Forest, Marine and ocean ecosystems, Issue 3.2. Soils, Forest Ecosystems, Marine and ocean ecosystems, 941-948.

[12] Constandache, C., Dinca, L., Popovici, L., Tudor, C. (2019). The role of forest vegetation in the mitigation of the ecological imbalances resulting from climate change in Putna-Vrancea river basin, International Symposium "The Environment and the Industry", SIMI 2019, Proceeding book, 98-106.

[13] Crisan, V.E., Dinca, L.C. (2020), Analysis of chemical properties of forest soils in Dobrogea Plateau. Revista de Chimie, 71(2): 267-272. 
[14] Crișan, V.E., Dincă L.C., Decă S.Ș. (2020). Analysis of chemical properties of forest soils from Bacau County, Revista de Chimie, 71(4): 81-86.

[15] Culvenor, D. (2010). Phenological change detection while accounting for abrupt and gradual trends in satellite image time series, Remote Sens. Environ., 114: 2970-2980.

[16] De Jong, R.S., De Wit, A., Schaepman, M.E., Dent, D.L. (2011). Analysis of monotonic greening and browning trends from global NDVI time-series, Remote Sens. Environ., 115: 692-702.

[17] Dinca, L., Nita, M.D., Hofgaard, A., Alados, C.L., Broll, G., Borz, S.A., Wertz, B., Monteiro, A.T. (2017). Forests dynamics in the montane-alpine boundary: a comparative study using satellite imagery and climate data, Climate Research, 73 (1-2): 97-110.

[18] Dinca, L., Badea, O., Guiman, G., Braga, C., Crisan, V., Greavu, V., Murariu, G., Georgescu, L. (2018) Monitoring of soil moisture in Long-Term Ecological Research (LTER) sites of Romanian Carpathians, Annals of Forest Research, 61(2): 171-188.

[19] D'Odorico, P., Bhattachana, A., Davisa, K.F., Ravib, S., Christiane, W., Runyana, C.W. (2012). Global desertification: Drivers and feedbacks. Adv. Water Resour., 51: 326-344.

[20] [20] Elmore, A.J., Kaste, J.M., Okin, G.S., Fantle, M.S. (2008). Groundwater influences on atmospheric dust generation in deserts, J. Arid Environ., 72: 17531765.

[21] Engelstaedter, S., Kohfeld, K.E., Tegen, I., Harrison, S.P. (2003). Controls of dust emissions by vegetation and topographic depressions: An evaluation using dust storm frequency data. Geophys. Res. Lett., 30 1294.

[22] Enescu, C.M., Dincă, L., Timofte, A.I. (2019). Main characteristics of forest soils across Getic Piedmont (South-Western Romania) - Scientific Papers. Series A. Agronomy, 62(1): 42-48.

[23] Evans, J., Geerken, R. (2004), Discrimination between climate and human-induced Dryland degradation, J. Arid Environ., 57: 535-554.

[24] Gbeckor-Kove, N. (1989), Drought and Desertification, World Meteorological Organization, Geneva, Switzerland, 41-73.

[25] Geist, H.H.J., Lambin, E.F. (2004). Dynamic Causal Patterns of Desertification, Bioscience, 54, 817-829.

[26] Gibbs, H.K., Salmon, J.M. (2015). Mapping the world's degraded lands, Appl. Geogr., 57: 12-21.

[27] Kaufman, Y.J., Tanre, D., Boucher, O. (2002). A satellite view of aerosols in the climate system, Nature, 419: 215-223.

[28] Koutroulis, A.G. (2019). Dryland changes under different levels of global warming. Sci. Total Environ., 655: 482-511.

[29] Lal, R., (2001). Soil degradation by erosion, Land Degrad. Develop. 12: 519-539.
[30] Lavauden, L. (1927). Les forêts du Sahara, Revue des Eaux et Forêts, Nancy, Paris, Strasbourg: Impr. Berger-Levrault, p. 329-341.

[31] Liu, Y.Y., Evans, J.P., Mccabe M.F. (2013). Changing climate and overgrazing are decimating Mongolian steppes, PloS One, 8, e57599. 1-6.

[32] Ministry of forestry and water affairs, 2015-2023, National Strategy and action plan to combat desertification, (2015-2023), General Directorate of Combating Desertification and Erosion, Republic of Turkey, $140 \mathrm{p}$.

[33] Mirzabaez, A., Wu, J., Evans, J., Garcia-Oliva, F., Hussein, I.A.G., Iqbal, M.H., Kimutai, J., Knowles, T., Meza, F., Nedjroaoui, D. (2019). Desertification. In Climate Change and Land: An IPCC Special Report on Climate Change, Desertification, Land Degradation, Sustainable Land Management, Food Security, and Greenhouse Gas Fluxes in Terrestrial Ecosystems, IPCC: Ginevra, Switzerland.

[34] Oneț, A., Dincă, L., Teușdea, A., Crișan, V., Bragă, C., Enescu, R., Oneț, C. (2019). The influence of fires on the biological activity of forest soils in Vrancea, Romania, Environmental Engineering and Management Journal, 18 (12): 2643-2654.

[35] Popov, E., Hinkov, G., Kachova, V., Constandache, C., Dincă L. (2017). A brief review of forest shelter belt establishments in Bulgaria and Romania, Revista de Silvicultură și Cinegetică, (41): 16-23.

[36] Prăvălie, R. (2016), Drylands extent and environmental issues, A global approach, EarthScience Rev., 161: 259-278.

[37] Reed, M.S., Buenemann, M., Atlhopheng, J., AkhtarSchuster, M., Backmann, F., Bastin, G., Bigas, H., Chanda, R., Dougill, A.J., Essahli, W., Evely, A.C., Fleskens, L., Geeson, N., Glass, J.H., Hessel, R., Holden, J., Ioris, A. A. R., Kruger, B., Liniger, H.P., Mphinyane, W., Nainggolan, D., Perkins, J., Raymond, C.M., Ritsema, C.J., Schwilch, G., Sebego, R., Seely, M., Stringer, L.C., Thomas, R., Twomlow, S., Verzadvoort, S. (2011). Cross-scale monitoring and assessment of land degradation and sustainable land management: A methodological framework for knowledge management, L. Degrad. Dev., 22: 261-271.

[38] Türkeș, M. (1999). Vulnerability of Turkey to desertification with respect to precipitation and aridity conditions, Turkish J. Eng. Environ. Sci., 23: 363-380.

[39] U. U. N. C. T. C. Desertification, (1994), Intergovernmental Negotiating Committee for a Convention to Combat Desertification, Elaboration of an International Convention to Combat Desertification in Countries Experiencing Serious Drought and/or Desertification, Particularly in Africa., in U.N. Doc. A/AC.241/27, 33 I.L.M. 1328., New York: United Nations.

[40] Unccd, (1994). Elaboration of an international convention to combat desertification in countries experiencing serious drought and/or desertification, particularly in Africa. General Assembly, United Nations, 1-58. 
[41] Verbesselt, J., Hyndman, R., Zeileis, A., Le, Q.B., Nkonya, E., Mirzabaez, A. (2016b). Biomass productivity-based mapping of global land degradation hotspots, In: Economics of Land Degradation and Improvement, A Global Assessment for Sustainable Development, University of Bonn, 55-84.

[42] Vizitiu, D.E., Dinca, L., Enache, V., Donici, A., Popa, L., Cociorva, D., Murariu, G. (2018), Identifying and describing the main climatic and stress factors that are affecting forest and vinicultural ecosystems, INTERNATIONAL SYMPOSIUM "THE ENVIRONMENT AND THE INDUSTRY", SIMI 2018, PROCEEDINGS BOOK Section Pollution Assessment \& Management Systems, 232-241.
[43] Wang, L. (2008). The limits of water pumps, Science, 321 (5885), 36-7.

[44] Zhu, Z., Piao, S., Myneni, R.B., Huang, M. (2016). Greening of the Earth and its drivers, Nat. Clim. Chang., 6: 791-795. 